LED 防犯灯 一不快グレアと照明環境の評価一

\title{
街路環境の主観評価 一相関色温度の影響一
}

Subjective Evaluation of Atmosphere of Environment Under LED Street Lights Using

Different Correlated Color Temperature

\キーワード : LED, 相関色温度, 防犯灯, 主観評価

$\triangle$ KEYWORDS : LED, correlated color temperature, subjective assessment, street light

\section{ABSTRACT}

The action of the Research \& Investigation Committee on Glare of LED Lighting Fixtures in Outdoor Lighting Environments is to examine whether the correlated color temperature affects the glare discomfort factor, visibility of human face and evaluations on environment under LED street lights.

In this study, the purpose is to provide the data using LED test lights with seven different correlated color temperatures ranging from $2800 \mathrm{~K}$ to $12000 \mathrm{~K}$ in a recreated night-time street atmosphere.

The results of this evaluation show street brightness, sense of security, color differentiation, cool/warm feeling, preference of atmosphere and adequateness of lighting under average illuminance on a recreated road surface set at 2 to $5 \mathrm{~lx}$. Therefore, the all evaluations are affected by the correlated colour temperature in positions nearer to the targets. The lower correlated color temperature lights are evaluated more preferable than the higher correlated color temperature lights.

\section{1.はじめに}

2 年間に渡り委員会で実施した実験については, 2013 年の日中韓ライティングカンファレンス ${ }^{1)}$, および2014 2015年の $\mathrm{CIE}^{2)-5)}$ で結果を報告した. 今月号の企画ではこ

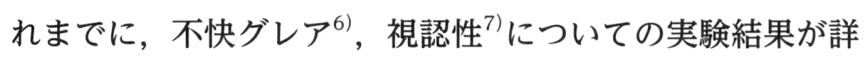
細に紹介されている. 続いて本報では, 主に LED 光源の 相関色温度と街路環境の主観評価の関係を明らかにするた めに, ブロック塀, レンガ塀, 生垣を模した壁紙と疑似蔦
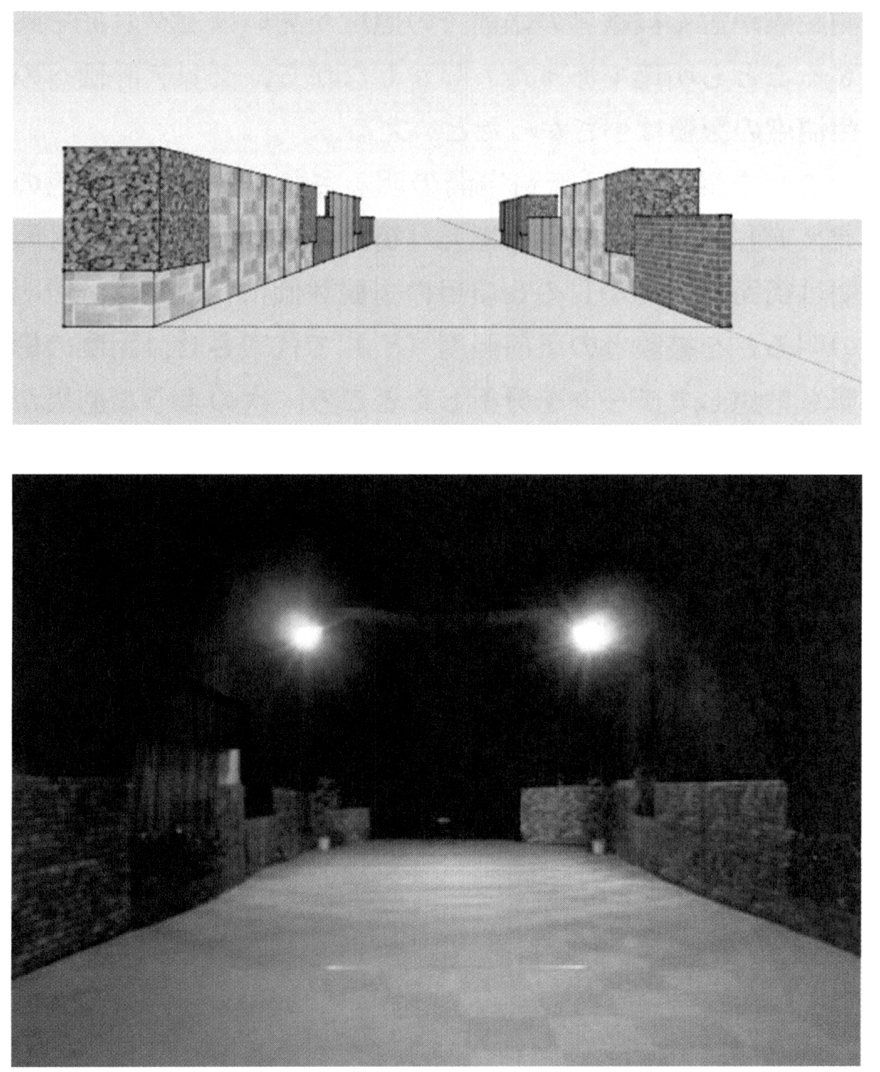

図1 実験用街路 (上 : パース, 下 : 照明器具 (実験時はいずれか一 方を点灯))

Fig.1 Test environment (top : plan, bottom : LED lights (evaluated under one light)).
を用いて作成した模擬生活道路環境（図 1 , パナソニック (株エコソリューションズ社大阪本社実験室内に設定）を作

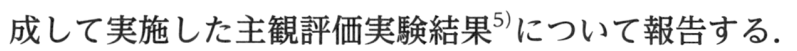

\section{2. 主観評価実験}

\section{1 主観評価項目}

周辺視によるグレア評価実験と同時に, 図 2 に示す評価 位置 D・E・F 地点において, 「街路空間の明るさ」,「安心 感」,「色の見え方」, 「照明光の温冷感」, 「街路の雾囲気の 好み」,「照明は街路に適切か」の6 項目について主観評価 を行った。 それぞれ図 3 に示す 7 段階の評価スケールを用 いた.

\section{2 実験環境}

20代の男性6名, 女性17名, 計23名の被験者全員の評価 結果を対象として集計を行った. 視距離 $5 \mathrm{~m}$ での被験者の 両眼視力は 1.0 が 4 名, 1.5が14名, 2.0-2.5が 5 名であった.

街路照明には表 1 に示す相関色温度，2800，3100, 3800, 5100,6300,8200, 12000 [K] の7種類の LED 照明を用いた. その際の路面平均照度は表 2 のとおりである.

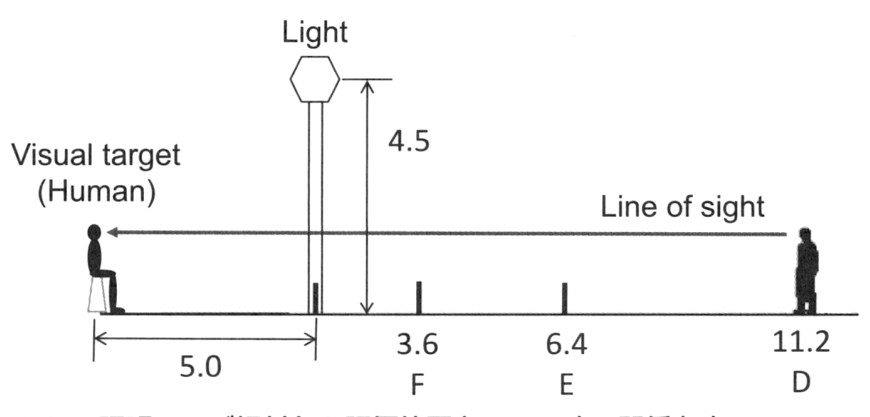

図 2 照明および視対象と評価位置 $(D \cdot E \cdot F)$ の関係 $(m)$

Fig.2 Positions and distances $(m)$ of observers (D, E, F), a visual target and light $(\mathrm{m})$. 


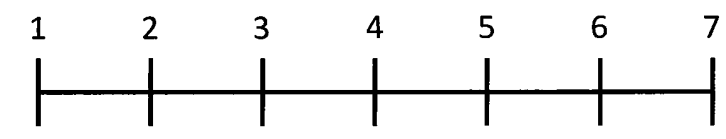

暗すぎる

暗い

明るい

明るすぎる

a）街路空間の明るさ

a) Street brightness.

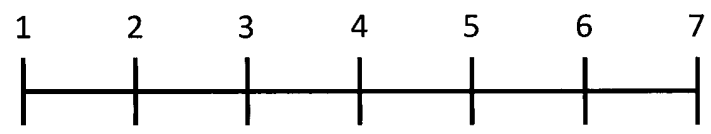

不安

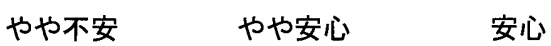

b) 安心感

b) Sense of security.
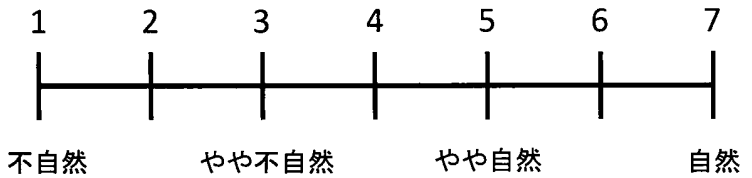

c）色の見え方

c) Color differentiation.

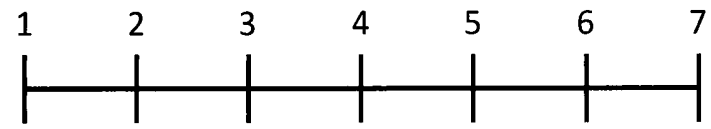

泠たい

やや泠たい

やや暖かい

暖かい

d) 照明光の温冷感

d) Cool/warm feeling.

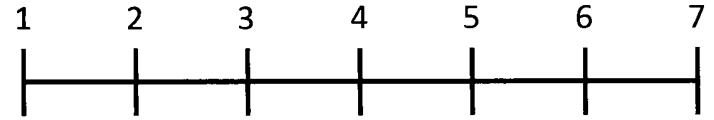

嫌い やや嫌い やや好き 好き

e）街路の需围気の好み

e) Preference of atmosphere.

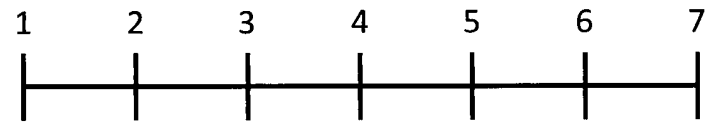

不適切

やや不適切 やや適切

適切

f）照明は街路に適切か

f) Adequateness of lighting.

図 3 評価項目と評価スケール

Fig.3 Evaluation scales.

\section{3. 評価結果}

グレア評価実験では，光源の輝度分布データを用いて， 最大輝度，最大輝度の $1 / 10$ および $1 / 100 の$ 輝度領域内の平
表 1 実験用光源と相関色温度

Table 1 Correlated color temperatures of the test lights.

\begin{tabular}{c|l|c}
\hline No. & \multicolumn{1}{|c|}{ 光源 } & 相関色温度 \\
\hline 1 & LED 街路灯 $2800 \mathrm{~K}$ & $2800 \mathrm{~K}$ \\
\hline 2 & LED 街路灯 $2800 \mathrm{~K}+\mathrm{B} 2$ フィルター & $3100 \mathrm{~K}$ \\
\hline 3 & LED 街路灯 $2800 \mathrm{~K}+\mathrm{B} 4$ フィルター & $3800 \mathrm{~K}$ \\
\hline 4 & LED 街路灯 $5100 \mathrm{~K}$ & $5100 \mathrm{~K}$ \\
\hline 5 & LED 街路灯 $5100 \mathrm{~K}+\mathrm{B} 2$ フィルター & $6300 \mathrm{~K}$ \\
\hline 6 & LED 街路灯5100K + B3フィルター & $8200 \mathrm{~K}$ \\
\hline 7 & LED 街路灯5100K + B4フィルター & $12000 \mathrm{~K}$ \\
\hline
\end{tabular}

表 2 街路の路面平均照度

Table 2 Area-average horizontal illuminance for all conditions.

\begin{tabular}{c|c|c|c|c}
\hline 相関色温度 & \multicolumn{4}{|c}{ 路面平均照度 (lx) } \\
\hline 2800 & 1.8 & 3.6 & 5.9 & 8.5 \\
\hline 3100 & 2.0 & 3.9 & 5.3 & 6.9 \\
\hline 3800 & 1.6 & 2.9 & - & - \\
\hline 5100 & 2.2 & 4.0 & 7.0 & 10.0 \\
\hline 6300 & 2.4 & 4.6 & 7.0 & 10.3 \\
\hline 8200 & 2.2 & 4.4 & 6.8 & - \\
\hline 12000 & 1.9 & 3.6 & 5.7 & - \\
\hline
\end{tabular}

均輝度，輝度積分值，有効グレア輝度と，グレア評価との 関係を検討した。それぞれ相関が認められるとともに，観 測距離が短く被験者の眼前での照度が高いほどグレアを感 じることも明確であった。 しかしながら，グレア評価への 色温度の影響は小さかったといえる.

これを受けて,「街路空間の明るさ」,「安心感」,「色の 見え方」,「照明光の温冷感」,「街路の䨌囲気の好み」,「照 明は街路に適切か」の6 項目の主観評価については, 照明 の明るさを被験者の眼前照度 $\left(E_{V}\right)$ で代表させ, 距離の影 響も考慮してデータを分析したところ，次のような結果が 得られた。なお，各評価項目について，有意水準 $5 \%$ で, 距離（地点）間，色温度間の分散分析を行ったところ，全 て有意差が認められた。

\section{1 街路空間の明るさ}

図 4に，街路空間の明るさ評価と眼前照度との関係を示

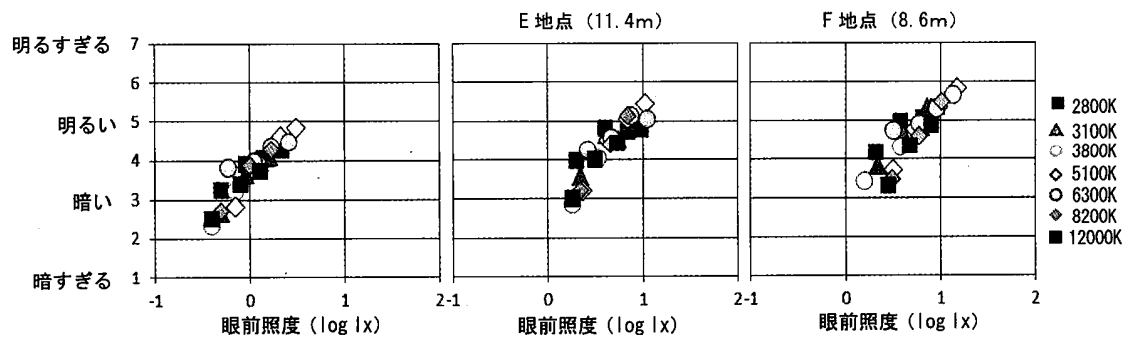

図 4 街路空間の明るさ評価と眼前照度の関係

Fig.4 Relationship between the evaluation score of street brightness and $E_{v}$. 


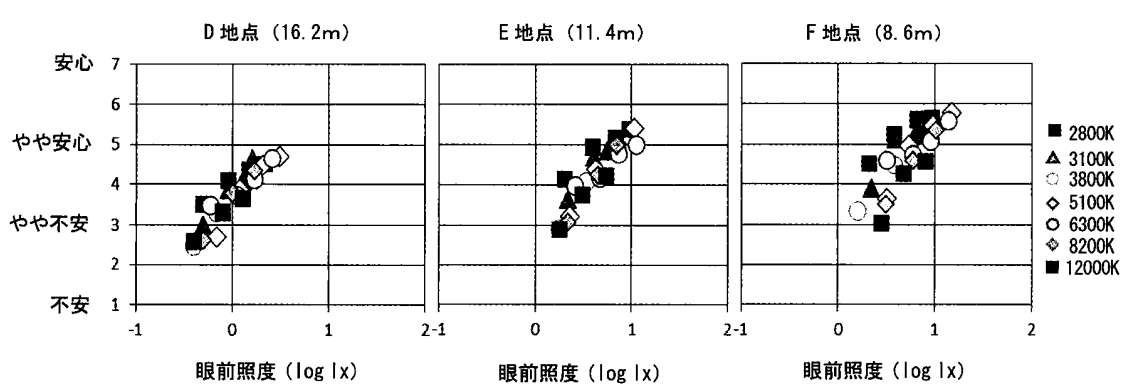

図 5 不安感評価之眼前照度の関係

Fig.5 Relationship between the evaluation score of sense of security and $E_{v}$.
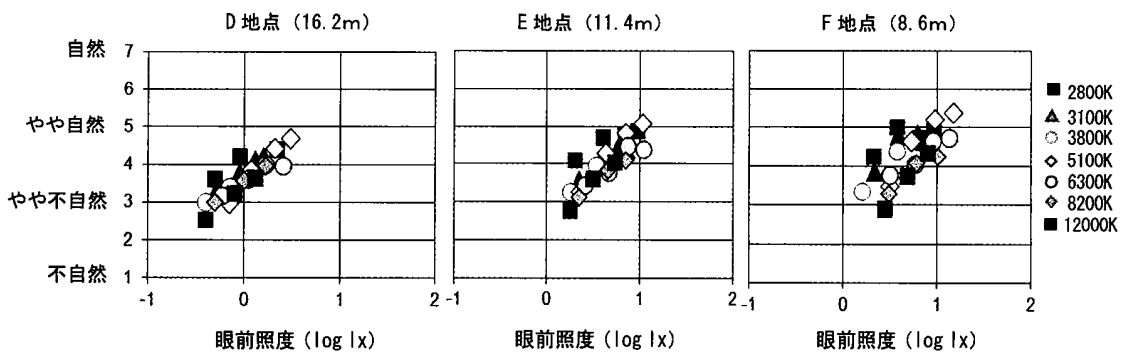

図6 色の見え方評価之眼前照度の関係

Fig.6 Relationship between the evaluation score of color differentiation and $E_{v \text {. }}$.
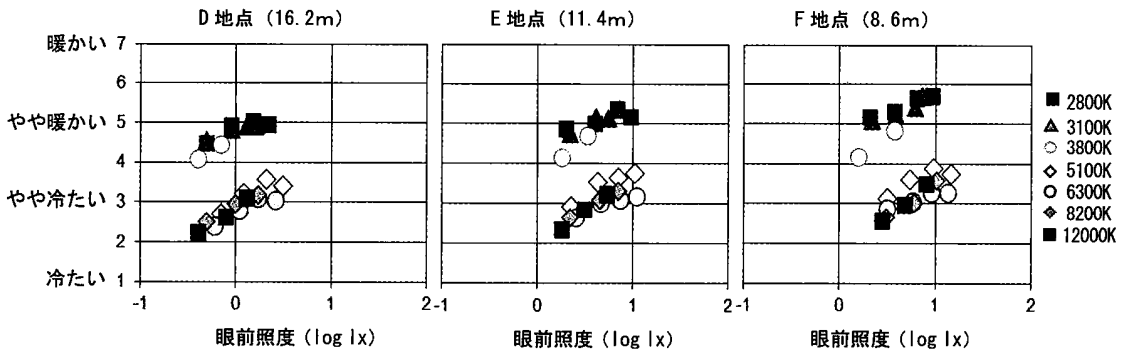

図7照明光の温冷感評価と眼前照度の関係

Fig.7 Relationship between the evaluation score of cool / warm feeling and $E_{v}$.

す．眼前照度が高くなると街路空間の明るさ評価は明るい 側に評価される傾向が明らかである．また，地点 $\mathrm{D} \rightarrow \mathrm{E} \rightarrow$ $\mathrm{F}$ と距離が近づくにしたがって, より強く相関色温度の影 響を受け，相関色温度が低いほど明るい側に評価されるこ とがわかる.

\section{2 安心感}

図 5 に, 安心感評価と眼前照度との関係を示す. 眼前照 度が高くなると安心感評価は安心側に評価される傾向が明 らかである. また, 地点 $\mathrm{D} \rightarrow \mathrm{E} \rightarrow \mathrm{F}$ と距離が近づくにし たがって, より強く相関色温度の影響を受け, 相関色温度 が低いほど安心側に評価されることがわかる.

\section{3 色の見え方}

図6に，色の見え方評価と眼前照度との関係を示す. 眼前 照度が高くなると色の見え方は自然に見える側に評価される 傾向が明らかである. また, 地点 $\mathrm{D} \rightarrow \mathrm{E} \rightarrow \mathrm{F}$ と距離が近付 くにしたがって, より強く相関色温度の影響を受け, 相関色 温度が低いほど自然に見える側に評価されることがわかる.

\section{4 照明光の温冷感}

図 7 に, 照明光の温冷感評価と眼前照度との関係を示す. 眼前照度が高くなると温冷感評価は暖かい側に評価される 傾向が明らかであり, かつ, 3800K 以下は暖かい側, $5100 \mathrm{~K}$ 以上は冷たい側に二分される. また，地点 $\mathrm{D} \rightarrow \mathrm{E} \rightarrow$ $\mathrm{F}$ と距離が近づくにしたがって, 相関色温度が低いほど暖 かい側に評価されることがわかる.

\section{5 街路の雲囲気の好み}

図8に, 街路の雾囲気の好みと眼前照度との関係を示す. 眼前照度が高くなると需囲気の好み評価は好き側に評価さ れる傾向が明らかである. 地点 $\mathrm{D} \rightarrow \mathrm{E} \rightarrow \mathrm{F}$ と距離が近づく にしたがって, より強く相関色温度の影響を受け, 相関色 温度が低いほど好まれる側に評価されることがわかる.

\section{6 照明は街路に適切か}

図9に，照明は街路に適切かの評価と眼前照度との関係 を示す．眼前照度が高くなると照明が街路に適切か評価は 適切側に評価される傾向が明らかである．また，地点 $\mathrm{D} \rightarrow \mathrm{E} \rightarrow \mathrm{F}$ と距離が近づくにしたがって，より強く相関 


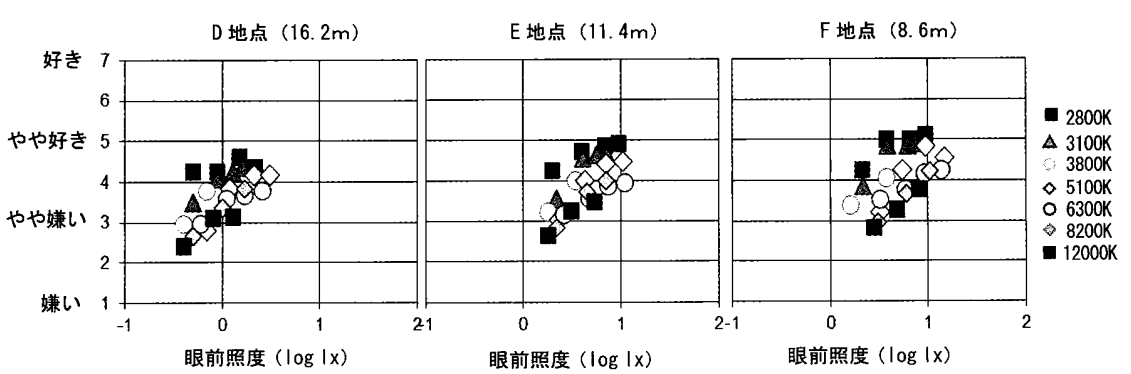

図 8 街路の雾囲気評価と眼前照度の関係

Fig.8 Relationship between the evaluation score of preference of atmosphere and $E_{v}$.

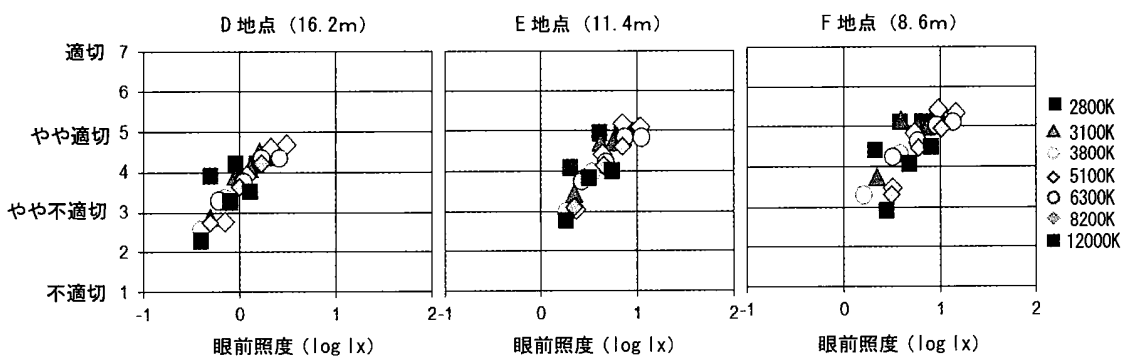

図 9 照明は街路に適切か評価と眼前照度の関係

Fig.9 Relationship between the evaluation score of adequateness of lighting and $E_{v}$.

色温度の影響を受け, 相関色温度が低いほど適切側に評価 されることがわかる.

\section{4.まとめ}

本研究では， 7 種の異なる相関色温度の LED 照明を用 いて, 模擬街路空間において歩行者の主観評価実験を行っ た. 得られた知見を以下に示す.

1）すべての評価において，距離が近いほど相関色温度の 影響を受ける.

2）照度が高いほど街路空間は明るい側に評価される.さ らに，距離が近いほど低相関色温度がより明るい側に評 価される。

3）照度が高いほど安心感は安心側に評価される.さらに, 距離が近いほど低相関色温度がより安心側に評価される.

4）照度が高いほど色の見え方は自然に見える側に評価さ れる.さらに，距離が近いほど低相関色温度がより自然 に見える側に評価される.

5）照度が高いほど温冷感評価は暖かい側に評価される. 相関色温度が3800K 以下は暖かい側，5100K 以上は冷 たい側に二分される．さらに，距離が近いほど低相関色 温度がより暖かい側に評価される。

6）照度が高いほど街路の需囲気は好まれる側に評価され る.さらに，距離が近いほど低相関色温度がより好まれ る側に評価される。

7）照度が高いほど照明は街路に適切か評価は適切側に評 価される.さらに，距離が近いほど低相関色温度がより 適切側に評価される。

\section{謝辞}

本研究はJLEDS より委託を受け, 照明学会「屋外環境 における LED 照明器具のグレアに関する研究調查委員会」 において実施された。 JLEDS および当委員会関係者に対 し，ここに記して謝意を表す。

1) Mori T. et al. : The Discomfort Glare Improvement Methology of LED Street Lights, Proceedings of the CJK Lighting Conference (2013).

2) Kohko S. et al. : Glare of LED Lighting in Outdoor Environment. Proceedings of the Lighting Quality and Energy Efficiency, CIE2014.

3) Iwata M. et al. : Visibility Evaluation for Face of Person Standing Under LED Street Lighting Environment. Proceedings of the Lighting Quality and Energy Efficiency, CIE2014.

4) Ayama M. et al. : Discomfort Glare of LED Street Lights with Different Correlated Colour Temperatures, CIE2015.

5) Iwata $M$. et al. : Appearance of Human Face and Atmosphere of Environment Under LED Street Lights Using Different Correlated Colour Temperature, CIE2015.

6）江湖俊介：歩行者のための不快ブレア評価，照学誌，99-9, pp.517-520 (2015).

7) 井上容子 : LED 防犯灯下の視認性 : 光量と色温度の影響, 照学誌, 99-9, pp.521-524 (2015).

\section{連絡先}

摂南大学 理工学部 住環境デザイン学科

テ572-8508 大阪府寝屋川市池田中町17-8

Department of Living and Environmental Design,

Faculty of Science and Engineering,

Setsunan University

17-8, Ikeda-nakamachi, Neyagawa, Osaka, 572-8508, Japan

E-mail : michico@led.setsunan.ac.jp 